\title{
Long tracheal replacement or the philosopher's stone
}

\author{
Marc Boada $^{1}$, Rudith Guzmán ${ }^{1}$, Elena Sandoval ${ }^{2}$ \\ ${ }^{1}$ Department of Thoracic Surgery, ICR, Hospital Clínic, Barcelona, Spain; ${ }^{2}$ Department of Cardiovascular Surgery, ICCV, Hospital Clínic, \\ Barcelona, Spain \\ Correspondence to: Elena Sandoval, MD, FEBCTS. Department of Cardiovascular Surgery, ICCV, Hospital Clínic, C/Villarroel 170 Esc 15 th floor, \\ 08036 Barcelona, Spain. Email: esandova@clinic.cat.
}

Submitted Sep 02, 2019. Accepted for publication Nov 20, 2019.

doi: 10.21037/acs.2019.11.08

View this article at: http://dx.doi.org/10.21037/acs.2019.11.08

Short tracheal resection with a termino-terminal anastomosis is typically a safely performed procedure. However, replacement of segments longer than $50 \%$ of the tracheal length in adults and $30 \%$ in children has become a great challenge in thoracic surgery. Different tracheal substitutes have been attempted, both experimentally and in clinical practices, to replace long tracheal segments. These include synthetic materials, non-tracheal grafts, tracheal allografts, tailored tube conduits and most recently, biomaterials (1).

\section{Synthetic grafts and non-tracheal grafts}

Initial attempts with synthetic grafts and non-tracheal biological tissue were associated with the need for tracheal stenting and prosthesis in order to maintain airway patency (2). Presently, the use of stents carries significant problems. It increases the risk of developing granulation tissue with subsequent obstruction, risk of infection and erosion into adjacent structures, as well as migrations (3).

\section{Tracheal allografts}

The use of cadaveric tracheal allografts faces two primary obstacles. The first of these involves achieving good vascularization of the new tracheal graft, which is dependent on the compliance of a complex system of several branches (4). In order to overcome this hurdle, the new graft may be folded into a vascular pedicle, which will then feed the allograft. It will then be transplanted with the trachea in the orthotopic position (5). Recently, Delaware's group have successfully presented their results in 6 patients, who were able to be extubated and weaned from immunosuppression (6).
The second major difficulty involves restoring the tracheal endothelium. Initially, some groups stated that endothelial replacement is key to avoiding the development of granulation tissue, which could then cause airway stenosis and reduce the immunogenic response (7). However, other groups suggested that endothelial replacement of the new graft is not mandatory, as it could be prompted by intense coughing (8).

\section{Tailored tube conduits}

Several pedicled autologous tissues have been used to replace and recreate tracheal structure and function, avoiding vascularization and epithelialization problems. However, the issue of maintenance of structural patency arises once again. The omentum, bladder or skin, in combination with autologous cartilage or synthetic materials, have been reported to be in use (9). These techniques allow immediate replacement and avoid immunosuppression. This is of special interest to oncological replacements.

\section{Bioengineered tissue}

To resolve these concerns, some groups are currently developing 3D-printed bio-artificial tracheal scaffolds, which are further covered with chondrocytes. These have shown promising results, with lower rates of tissue necrosis and epithelial loss (7).

The need for long tracheal segment replacement is an infrequent but still unresolved surgical challenge. It faces three main obstacles: a necessity to mimic the mechanical properties of the trachea, graft viability and vascularization, and epithelial replacement (10). 
The value of a successful tracheal replacement modality cannot be overstated. Several groups are leading the research in both animal and clinical experiments with promising results. 3D-printed scaffolds, vascular flaps and endothelial seeding appear to be the key for success.

\section{Acknowledgments}

None.

\section{Footnote}

Conflicts of Interest: The authors have no conflicts of interest to declare.

\section{References}

1. Varma R, Aoki FG, Soon K, et al. Optimal biomaterials for tracheal epithelial grafts: An in vitro systematic comparative analysis. Acta Biomater 2018;81:146-57.

2. Martinod E, Seguin A, Holder-Espinasse $M$, et al. Tracheal regeneration following tracheal replacement with an allogenic aorta. Ann Thorac Surg 2005;79:942-8; discussion 949.

3. Cosano Povedano A, Muñoz Cabrera L, Cosano Povedano
FJ, et al. Endoscopic treatment of central airway stenosis: five years' experience. Arch Bronconeumol 2005;41:322-7.

4. Salassa JR, Pearson BW, Payne WS. Gross and microscopical blood supply of the trachea. Ann Thorac Surg 1977;24:100-7.

5. Delaere P, Van Raemdonck D, Vranckx J. Tracheal transplantation. Intensive Care Med 2019;45:391-3.

6. Hysi I, Kipnis E, Fayoux P, et al. Successful orthotopic transplantation of short tracheal segments without immunosuppressive therapy. Eur J Cardiothorac Surg 2015;47:e54-61.

7. Xia D, Jin D, Wang Q, et al. Tissue-engineered trachea from a 3D-printed scaffold enhances whole-segment tracheal repair in a goat model. J Tissue Eng Regen Med 2019;13:694-703.

8. Grillo HC. Tracheal replacement: a critical review. Ann Thorac Surg 2002;73:1995-2004.

9. Mercier O, Kolb F, Dartevelle PG. Autologous Tracheal Replacement: Surgical Technique and Outcomes. Thorac Surg Clin 2018;28:347-55.

10. Den Hondt M, Vanaudenaerde B, Verbeken E, et al. Requirements for Successful Trachea Transplantation: A Study in the Rabbit Model. Plast Reconstr Surg 2018;141:845e-856e.

Cite this article as: Boada M, Guzmán R, Sandoval E. Long tracheal replacement or the philosopher's stone. Ann Cardiothorac Surg 2020;9(1):58-59. doi: 10.21037/ acs.2019.11.08 